\title{
Affordances of Nearby Forest and Orchard on Children's Performances
}

\author{
Ismail Said \\ Associate Professor, Faculty of Built Environment, \\ Universiti Teknologi Malaysia, Malaysia \\ b-ismail@utm.my
}

\begin{abstract}
This research investigated the performances of children and adolescents with the properties of a nearby forest and orchards in Malaysia. It measured the affordances of the natural setting including the topography, water bodies, vegetation and animals as experienced by them. Their performances were observed through a two-day hiking and camping programme in both the settings. Utilised affordances dominated the actions of the children and adolescents twice more than the combination of perceived and shaped affordances. The results suggested that the nearby forest and orchard were suitable playscapes for the children to express their physical as well as socialisation competences.
\end{abstract}

Keywords: forest park, children's functioning, plants, affordances

ISSN 2514-751X @ 2017 The Authors. Published for AMER ABRA by e-International Publishing House, Ltd., UK.. This is an open access article under the CC BY-NC-ND license (http://creativecommons.org/licenses/by-ncnd/4.0/). Peer-review under responsibility of AMER (Association of Malaysian Environment-Behaviour Researchers), ABRA (Association of Behavioural Researchers on Asians) and CE-Bs (Centre for EnvironmentBehaviour Studies), Faculty of Architecture, Planning \& Surveying, Universiti Teknologi MARA, Malaysia.

https://doi.org/10.21834/aje-bs.v2i3.184 


\subsection{Introduction}

A plethora of theories and empirical studies suggest that children's contact with the natural environment is crucial to their physical, social and cognitive development (Chawla and Heft, 2002). To children, natural environment provides a place to play (Fjortoft, 2004), transact with peers (Kytta, 2002), set boundaries to play within own sense of control (Olds, 1989), and understand the outer world (Taylor et al., 1998; Sebba, 1991). Experiencing nature permits children to attain fascination because they gain peace and quiet, tranquility, and moments of privacy.

Children experiencing outdoor environments such as forest gain an active living, dexterity and mobility. Forest allows young children to play a variety of sensorial and motoric activities including climbing rocks and trees, running and tumbling and sliding slopes (Fjortoft, 2004). Studies on children in outdoor environments suggest that children are attracted not to the forms and shapes of the outdoor features but to their functions (Fjortoft, 2004) which are their affordances (Gibson, 1979). Function is the interaction of children with the spatial elements in the ecosystem (Christensen, 2003). Heft (1999) explains how children perceive the function of environment and utilise them for play: if a tree is climbable it affords climbing; if a stone fits the hand it is grasp-able or throw-able and thus affords grasping and throwing. In other words, the functional meanings of the elements trigger children to interact with them. In as much, Said (2008) found that middle childhood children perceive boulders at river as climbable features that afford scaling, sitting, lookingout from and hiding. Thus, playing in nature means children are free to explore and interact with the natural elements with little or no restriction or supervision. Interaction with the natural world is direct and spontaneous (Chawla, 1992; Kellert, 2002). In short, direct experience of outdoor environments such as the forest stimulates children's cognitive, physical and social functions.

In Malaysia, $32 \%$ of the population (8.2 million) are children, and the majority of them who are living in cities and towns are disconnected from the outdoor environment for play and socialising. In fact, the children spend their time indoors and experience a sedentary lifestyle. As such, their understanding on functional properties of the forest such as sloping grounds, boulders, trees and fruits, insects and birds, and effects of wind and rain is very limited to the knowledge that they gain from books in schools. This vicarious method is a cognitive mode of learning Affordances of Nearby Forest and Orchard on Children's Performances that limits physical and social interactions (Kellert, 2002). This means that the children lack hands-on experience and know little how to manipulate plant elements into play tools such as making a slingshot from a Y-shaped tree branch. They neither know the names of plants and birds nor do they recognise that not all spiders are poisonous. In other words, their dexterity is low, and consequently, their cognitive performance is minimal 


\subsection{Literature Review}

\section{Performance properties of forest park}

Exposing the children to forest-liked environment such as nearby forest and orchard allows them to discover things themselves, in their own space and time. Direct experience with the natural environment permits various performatory activities through curiosity and discovery. For example, hiking on a forest trail can offer the children to discover that ants move in a long line and bump their heads when they meet. The experience involves motoric and sensorial performances (Kytta, 2003); the former is bodily movement and the latter is visual scanning and audio stimulation. The performances allow the children establish affection to the forest environment that they participate in, and later get attached to the place (Chawla and Heft, 2002). Furthermore, nature helps children acquire powers of observation and creativity and instills a sense of peace. Children learn best when they are able to discover things themselves, in their own space and time.

Apart from vegetation and animals, topography may offer children engagement in sensorial and motoric activities. Fjortoft (2004) found that young children recognised slopes and the roughness of the topography as a play habitat. The children utilised slopes for sliding, cliffs for climbing, and snowy hills for skiing. These are performatory as well as exploratory performances that develop children's motor skills including balance and coordination. Topography is integrated with stream configuration and its elements include boulders and sand, overarching trees, aquatic animals and the velocity of flow. An empirical study by Said (2008) suggests that stream environment affords 87 functional properties. For instance, graspable objects such as sand, pebbles and boulders permit the children to build sand mound, throw sand on peer's back, throw flat pebbles of water surface and collect small boulders to build a dam. In summary, the topography and stream of a forest landscape provide a variety of performances; performatory, discovery, production (Chawla and Heft, 2002). According to Kytta (2003), these performances are the result of integration of sensorial and motoric actions of children experiencing an environment. The experience may allow children to establish affection and attachment to the forest park environment (Kellert, 2002).

\section{Definition of concepts}

In this study, orchard is comprised of young and matured fruit trees of durios (durian), garcinias (mangosteen), parkia (petai), nepheliums (rambutan and pulasan), and lansium (langsat). These are seasonal tropical trees which are cultivated for their fruits generally in the months of April to May. The topography of the fruit farm is undulating from a gentle slope $(10$ to $15 \%)$ to a steep slope (20 to $30 \%$ ) with little undergrowth that permits the children to walk on its trails. It is located on an elevation of more than $650 \mathrm{~m}$ above sea level in a village, in Kampong Cheh in Cemor which is located in the state of Perak, Malaysia. 
Nearby forest is a secondary forest which is generated after its matured tree stands were harvested about 35 years ago. It is located at the periphery of the orchard and thus on higher elevations and steeper slopes that the orchard. Its undergrowth is dense with vines, gingers, licualas, rattans and plenty of tree saplings. Its canopy is mainly composed of low to medium height dipterocarpus trees with a few emergent trees such as Kompassia excelsa (Taulang) and Vatica indica (Resak). The dense vegetation and steep slopes are the main challenges that the children have to endure during a hike. There is a stream that originated from the forest and runs through the orchard and to the village landscapes.

\section{Aims and Scope of Study}

This research, therefore, investigates the affordances of a nearby forest and orchard on young children and adolescents experiencing the natural elements. It measures the functional properties of the forest topography, water bodies, vegetation and animals as experienced by the children, both in sensual and motoric modes. The unit of analysis consists of children and adolescents, aged 5-17 years, who interact with the forest elements in at least three types of activities: performatory, exploratory and productive (Chawla and Heft, 2002). The dependent variable is the children's performance, measured in the form of physical and social actions or activities. The independent variables are: (1) landscape elements which include the topography, water bodies, vegetation and animals that afford them physical and social play, and (2) the way they use those elements for play.

\subsection{Methodology}

\subsection{Data collection}

The physical and social activities of 18 children and adolescents are observed during a twoday participatory hiking and camping programme in a nearby forest and orchard setting at a village of Kampong Cheh in the Cemor district of Perak, Malaysia. The participants are boys from an orphanage called An Nur Maisarah which houses 31 orphans of varied background and income levels. Generally, most of them are from the villages and whose parents or caretakers have died or who are no longer able to support the children's livelihood. The researcher and his assistant together with the 18 children hiked from a camping site in the orchard located beside a stream. The children's actions were documented with a digital camera as well as in a field journal. Three tape recorders were given to three children, aged 5, 11 and 16 respectively, to elicit their words on the hiking experience. The group was led by a guide that knew the trails in the natural settings. From the camping site, the journey crossed a footbridge over the stream which attracted the children to stop and observe a landscape of weathered sandstone boulders which have been shaped by the running water of the stream. The guide was briefed by the researcher on the purpose of the participatory study, and thus hiking along the trails was according to 
the children's pace and demand. In the orchard, the group stopped at several points in the following order: under a cluster of durian trees bearing young fruits, under a $50 \mathrm{~m}$ tall Taulang tree, and on top of a hill near a hut (a vantage point) to taste the leaves of garcinias and to view the surrounding greenery. As the group approached the nearby forest, the guide informed them that they would encounter steep and slippery slopes, thorny rattan plants, thick undergrowth, and attack from leeches. As such, the children made a few stops at a stream and waterfall, on top of a slope, 5 and on large boulders. The experience in the forest was shorter than in the orchard because of the difficult conditions. The adolescents had to carry a few 5 to 6 year old peers on their back at this point of the journey. Once the group reached a ridge, they decided to turn back to the camping site in the orchard. The journey lasted for more than 3 hours. Upon reaching the camping site, all of them took a bath and played in the stream near to their camps.

\subsection{Data analysis}

Pictures from the camera were printed and then analysed to elicit the activities of the boys with the elements of nearby forest and orchard. The activities were tabulated and categorised into (1) level of affordances, (2) taxonomy of affordances, and (3) types of affordances (Kytta, 2003).

Similarly, notes from the field journal were bracketed (Denzin, 2001 ) into the categories of affordance. Recorded words of the participants were transcribed and later bracketed into the affordance categories. The three sets of data which were from the camera, field notes and recorder, were triangulated and the results are discussed in the following section.

\subsection{Results and Discussion}

The affordances of forest on the performances of children are discussed in three categories: level of affordances, taxonomy of affordances and types of affordances.

\subsection{Level of affordances}

The performances of the children are categorised into three levels of affordances: perceived, utilised and shaped (Kytta, 2003). The nearby forest and orchard offered 98 affordances to the children and adolescents, engaging them with 62 utilised activities, 30 perceived activities and only 6 shaped activities. The results suggested that the nearby forest and orchard afforded a variety of functional properties to engage the children's attention (Kytta, 2002) and to permit physical movement and competency (Kellert, 2002). This means that the rural setting is a natural environment affording a variety of elements and allowing the children to engage with plenty of physical movements and social actions. The children traversed across various hill slopes and valleys in a partial dense landscape of fruits -bearing trees in the orchard and dense landscape of trees and undergrowth in the nearby forest. Some of the utilised activities that they performed were hiking on a trail 
(Figure 1), picking durian fruits, plucking leaves, climbing slippery slopes, holding tree lets and rattan climbers, climbing slopes, ducking under a fallen log, picking pebbles from the stream bed, throwing pebbles on the water surface and throwing stones to a tree trunk. The utilised activities were associated with perceived ones such as feeling cold while swimming in the stream, observing bulbuls and magpie robins while swimming in the stream, watching peers searching for shrimps in the stream, and scanning and avoiding thorny rattan plants while climbing down the slopes. An example of a utilised activity was picking young durian fruits from under the trees in the orchard. An eight-year old boy collected the fruits and held them from their stalks, about three to five fruits in one hand. He said, "Look, nice and beautiful" to another five year old peer. "The spikes are soft, it is light" replied the younger peer. This means that the fruit afforded the child to interact and exchange words with his peer, and learn that young fruits were soft to touch and light to carry. This is a social affordance (Kytta, 2003) that generated acquaintanceship between the boys. It means that the boys were fascinated with the elements of the orchard through social interaction.

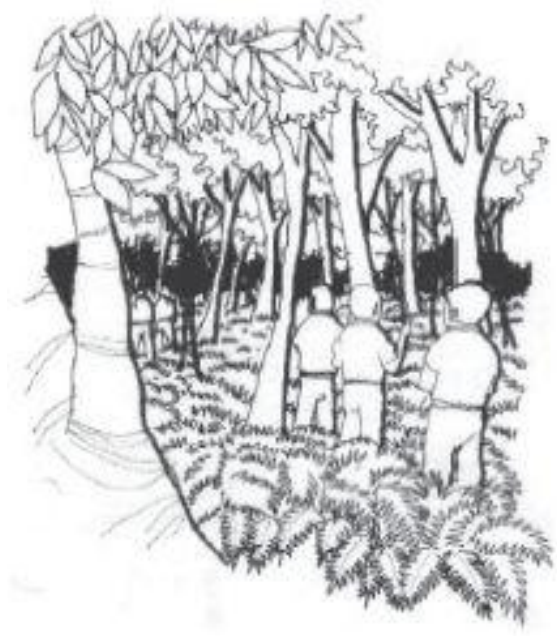

Figure 1: Hiking on a trail in the orchard

At the waterfall, the boys rested and had their meals which were brought by a few adolescents in their bags. Some sat on the boulders and others on footbridge looking at the fast flowing water under their feet. An eight-year old boy plucked a leaf from a tree and formed it into a boat using a tiny branch. He let the boat flow on the stream and later his action was followed by many of his peers. He demonstrated to them how to make the boat. This is a shaped affordance; building a play tool from the natural elements derived from past knowledge. 
At a steep and slippery slope in the nearby forest, the boys performed 7 a cooperative task assisting each other to get over a ridge. They had to step carefully avoiding the spikes of the rattan climbers that were in abundance. They pulled and pushed each other to climb the slope with a lot of laughter. This social interaction reflected from their cooperation of living in one orphanage that is like a large family. Thus, experiencing the forest allowed the children and adolescents to demonstrate their bond generated by the caretakers of the orphanage.

The results suggest that the nearby forest and orchard afforded a variety of functional properties to engage their attention (Kytta, 2003) and to permit physical movement and competency (Kellert, 2002). Notwithstanding, children only managed to manipulate four properties of the elements found in the nearby forest and orchard: making camp fire from fallen branches and logs, making a clothes-line with a bamboo pole to dry their clothes, and making a fishing rod by cutting a small branch of a tree and making toy boats from leaves. In short, the children in the forest and orchard enjoyed many opportunities, freely demonstrated their physical competences, interacted with features, and gained social skills.

\subsection{Taxonomy of affordances}

In the taxonomy of affordances, four properties that afforded the highest numbers of affordances were: water with 25 activities, vegetation with 22 activities, graspable or detached objects with 12 activities and environmental opportunities for sociality with 9 activities.

Water afforded the highest number of affordances in the nearby forest and orchard. Interestingly, in the stream, apart from swimming; the children searched for shrimps and scooped crustaceans such as snails and crabs using a plastic sieve; threw pebbles into the water; scooped sand with both hands from the stream bed; splashed water at their peers; rested on boulders; felt cold after staying long in the water; cooled their bodies after hiking in the forest; and felt water moving around their bodies. This finding is partially paralleled with a study by Said (2008) in which the forest stream affords 87 functional properties.

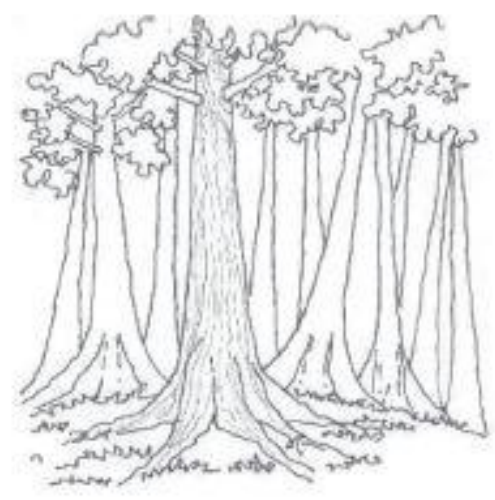


Figure 2: The slender trunk of huge monopodial treesattracted visual responses

Affordances of vegetation were picking young durian fruits, plucking young garcinia leaves, hurdling over fallen logs, holding tree lets to climb a slippery slope, and touching moss with the feet and hands. The result suggested that the nearby forest and orchard possessed a variety of elements for the children to play with. Not only did the children recognize the different parts of the vegetation, they were also able to identify the different types of branches of trees. Sixty percent of them recognised the monopodial tree over the sympodial ones (Figure 2). It appears that children were familiar with the sympodial trees found in their orphanage garden and thus were able to differentiate the unfamiliar and uncommon one, the monopodial type.

The graspable or detached objects afforded picking and collecting pebbles, fruit stalks, sand and dried leaves. For example, the elements of the orchard afforded the children to watch their peers throwing pebbles over water surface, scooping sand from stream bed (Figure 3), throwing stones to a tree trunk, and collecting branches for firewood and making fire. While hiking in the forest, the children pulled the garcinia leaves with a stick, plucked wild guava, picked yellow pods from the forest floor, cracked the pods to see red seeds, picked dried branches, grabbed the stalks of durian fruits, threw dried leaves into the river and watched the leaves drift on the water. In other words, by scanning the natural elements, the children were able to recognise the loose parts of the elements and use them as playing tools. The results also suggested that the nearby forests and orchards offered plenty of loose parts for children to grasp and use in their playing activities.

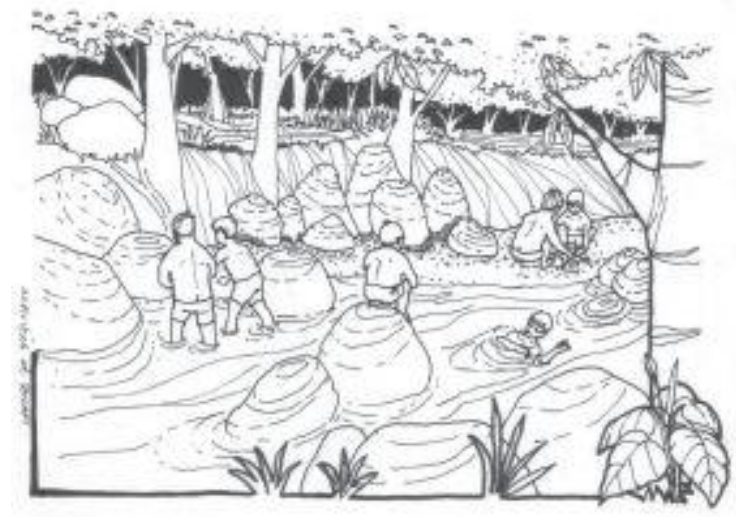

Figure 3: Children collecting pebbles from the stream bed and placing them on sand bars or boulders

Each affordance involved sensorial and motor actions, simultaneously. For example, sitting on the boulder involved scanning and selecting a suitable boulder to sit on; two 
sensorial actions. These actions triggered the child to climb and then sit on the boulder; two motor actions. In other words, through active detection of information and movement (Kytta, 2003), a boulder in a forest stream offered four properties to a child to experience. The nearby forest and orchard afforded multi-affordances for children to play and manipulate. Those affordances were balancing on boulders, sitting on boulders to eat lunch, cutting bamboo poles, making a cloth line from a bamboo pole, feeling irritated after cutting the bamboo, standing on the footbridge, observing huge trees and ducking under fallen logs. This means that children were familiar with that environment and its materials which perceptually generated attention and intention towards the affordances. In summary, the nearby forest and orchard were viewed by the children and adolescents as a suitable playscape. Perception and dexterity in the natural settings allowed them to exploit nature and learn about the utilitarian values of elements (Kellert, 2002). Additionally, the direct experience in nature permitted children to value the functional properties of naturalness of the forest and orchard; scanning, hearing, climbing, cutting, sitting, manipulating, standing, observing and ducking.

\subsection{Types of affordances}

The nearby forest and orchard offered 94 positive affordances but only four negative ones to the children. The positive affordances overwhelmed the negative ones suggesting that the functional properties of the nearby forest and orchard were effectively perceived and utilised by the boys. In other words, they perceived the orchard and the hill forest as places that afforded a variety of functional properties for playing and learning about nature. The four negative affordances were fear of the leeches, fear of the thorny rattan plants, tired after hiking the forest hill and climbing down the slope, and irritation on the skin after cutting the bamboo. However,the negative affordances were temporary attention stimuli (Sobel, 2002) because the positive ones overwhelmed the children's fears and anxieties. The vast difference between the number of positive and negative affordances suggested that the children had recognized the forest and orchard as play spaces offering fascinating sensorial and motoric activities.

\subsection{Conclusion}

The natural environment of a tropical woodland area is a suitable playscape for children to express their physical competences as well as to socialise. The familiar and comfortable environment, closeness, and the variety of natural elements in the forest settings afforded multi-affordances for the children to experience and play. Children's playing activities in this setting involved high performatory and exploratory performances including climbing and sliding down the slippery slopes, picking fallen fruits, plucking leaves from the trees, collecting pebbles from the stream bed and throwing them onto the stream surface, and many more. 
Hence, the nearby forest and orchard were ecological systems comprising of a diversity of vegetation and animals as well as topographical and stream variations. They allowed the children to explore and discover the elements of nature through physical and social participations. They possessed a variety of potentialities for children to play within their own perceptual, sensorial and motoric abilities. They afforded limitless number of play modes that fascinated the children. Inasmuch, it is a natural playscape for training of motor fitness in children as well as learning about the natural environment (Fjortoft and Sageie, 2000). Finally, they afforded the children to understand the worthiness of nature, the dependence of animals on plants, the opportunity to explore and discover, the manipulation of natural materials into play tools, and the physical attraction and appeal of nature.

\section{References}

Chawla, L. (1992). Childhood Place Attachments. In: Altman, I. and Low, S. M. eds. Place Attachment, New York and London: Plenum Press, 63-86.

Chawla, L \& Heft, H. (2002). Children's competence and the ecology of communities: a functional approach to the evaluation of participation, Journal of Environmental Psychology, 22, 201-216.

Christensen, P. (2003). Place, Space and Knowledge: Children in The Village and The City In: Christensen, P. and O'Brien, M.: Children in The City: Home, Neighbourhood and Community: The Future of Childhood Series, Routledge Falmer, Taylor \& Francis Group, London and NY, 13-28.

Denzin, N. K. (2001). Interpretive Interactionism. Sage Publications, London.

Fjortoft, I. \& Sageie, J. (2000). The natural environment as a playground for children: Landscape description and analyses of a natural playscape. Landscape and Urban Planning, 48, 83-97.

Denzin, N. K. (2001). Interpretive Interactionism. Sage Publications, London. Fjortoft, I. \& Sageie, J. (2000). The natural environment as a playground for children: Landscape description and analyses of a natural playscape. Landscape and Urban Planning, 48, 83-97.

Fjortoft, I. (2004). Landscape as Playscape: The Effects of Natural Environments on Children's Play and Motor Development, Telemark University College, Journal of Children's Environments Quarterly.14 (2), 21-44

Gibson, J. J. (1979). The Ecological Approach to Visual Perception. Boston: Houghton Mifflin.

Heft, H. (1999). Affordances of Children's Environments: A Functional Approach to Environmental Description. In: Nassar, J. J. and Preiser, W. F. E. eds.

Directions in Person-Environment Research and Practice, Aldershot: Ashgate, 44-69.

Kellert, R. S. (2002). Experiencing Nature: Affective, Cognitive and Evaluative Development in Children In: Kellert, S. R. and Kahn, P. H., Children and Nature: Psychological, Sociocultural, and Evolutionary Investigations, The MIT Press Cambridge, Massachusetts London, England. 
Kytta, M. (2002). Affordances of Children's Environments In: The Context of Cities, Small Towns, Suburbs and Rural Villages In Finland And Belarus, Landscape and Urban Planning 48. Journal of Environmental Psychology $22,109-123$.

Kytta, M. (2003). Children in Outdoor Contexts: Affordances and Independent Mobility in the Assessment of Environment Child Friendliness. Centre for Urban and Regional Studies, Helsinki University of Technology, Doctoral Thesis.

Said, I. (2008). Evaluating Affordances of Streams and Rivers Pertaining to Children's Functioning in Natural Environment, Journal of King Saud University—Architecture and Planning Division, Vol. 20, 50-65.

Sebba, R. (1991). The Landscape of Childhood: The Reflection of Childhood's Environment in Adult Memories and in Children's Attitudes. Environment and Behavior, 4, 23, 395-422.

Sobel, D. (2002). Children's Special Places: Exploring the Role of Forts, Dens, and Bushe Houses in Middle Childhood, Wayne State University Press, Detroit.

Taylor, F. A. \& Kuo, F. E. (2006). Children's Experience of Places: Is Contact with Nature Important for Healty Child Development? State of The Evidence, In: Spencer, C., and Blades, M., Children and their Environments: Learning, Using and Designing Spaces, Cambridge University Press, United Kingdom,124-140. 